\title{
Laminar to turbulent transition on the HIFiRE-1 cone at Mach 7 and high angle of attack
}

\author{
Sebastian Willems* and Ali Gülhan ${ }^{\dagger}$ \\ Institute of Aerodynamics and Flow Technology, German Aerospace Center (DLR), 51147 Köln, Germany \\ Thomas J. Juliano $\ddagger$ \\ National Research Council Associate, Beavercreek, OH 45324, USA \\ Steven P. Schneider $\$$ \\ School of Aeronautics and Astronautics, Purdue University, West Lafayette, IN 47907-1282, USA
}

\begin{abstract}
During the descent phase of the transition flight experiment HIFiRE-1 the angle of attack was higher than expected, since an anomaly occurred in the exoatmospheric pointing maneuver. All pre-flight ground tests were carried out at angles of attack below $6^{\circ}$. Therefore several post-flight experiments at high angles of attack were performed in the hypersonic wind tunnel (H2K) of the German Aerospace Center in Cologne. The selected Mach number of 7 and the Reynolds number range cover the flow conditions of the flight phase which are relevant for the transition experiment. The test campaign included highfrequency surface pressure measurements with $\mathrm{PCB}^{\circledR}$ sensors and heat flux measurements by means of quantitative infrared thermography. The results show significant effects of the emerging crossflow vortices on the transition location and the pressure fluctuations in the boundary layer.
\end{abstract}

\section{Nomenclature}

$\begin{array}{llc}\alpha & \text { angle of attack } & \circ \\ \Phi & \text { azimuthal angle to windward ray } & \circ \\ M a & \text { Mach number } & 1 \\ p_{0} & \text { reservoir pressure } & \mathrm{kPa} \\ p_{\infty} & \text { freestream pressure } & \mathrm{Pa} \\ r_{N} & \text { nose radius } & \mathrm{mm} \\ R e_{u, \infty} & \text { freestream unit Reynolds number } & \frac{1}{\mathrm{~m}} \\ T_{0} & \text { reservoir temperature } & \mathrm{K} \\ T_{\infty} & \text { freestream temperature } & \mathrm{K} \\ x & \text { coordinate in flow direction } & \mathrm{mm} \\ y & \text { coordinate horizontal } & \mathrm{mm} \\ z & \text { coordinate vertical } & \mathrm{mm}\end{array}$

\footnotetext{
* Research Assistant, Supersonic and Hypersonic Technology Department. Member AIAA.

${ }^{\dagger}$ Head of Department, Supersonic and Hypersonic Technology Department. Member AIAA.

${ }^{\ddagger}$ Research Associate. Member AIAA.

$\S$ Professor. Associate Fellow AIAA.
} 


\section{Introduction}

In the frame of the scientific cooperation an experimental study dedicated to the post flight analysis of the HIFiRE-1 flight experiment was carried out in the hypersonic wind tunnel H2K of DLR. The primary objective was the study of the laminar to turbulent boundary layer transition on a $7^{\circ}$ half-angle cone at high angles of attack up to $15^{\circ}$. To match the conditions of the flight experiment all tests were carried out at Mach 7 varying the unit Reynolds number between 5.5 and $11.5 \cdot 10^{6} \frac{1}{\mathrm{~m}}$. The test campaign included highfrequency surface pressure measurements using $\mathrm{PCB}^{\circledR}$ sensors and heat flux measurements via quantitative infrared thermography. The paper of Juliano et al. ${ }^{1}$ concentrates on the measured pressure fluctuations, whereas the focus of this paper are the results of the heat flux measurements.

\section{I.A. Background}

The Hypersonic International Flight Research Experimentation (HIFiRE) program is a hypersonic flight test program executed by the Air Force Research Laboratory (AFRL) and the Australian Defence Science and Technology Organization (DSTO) $)^{2,3}$. Its purpose is to develop and validate technologies critical to next generation hypersonic aerospace systems. The HIFiRE- 1 payload consisted of a $7^{\circ}$ half-angle cone with a $2.5 \mathrm{~mm}$ nose radius and a $33^{\circ}$ flare. The cone was devoted to the boundary-layer transition (BLT) experiment and the flare to the shock-wave/boundary-layer interaction (SWBLI) experiment. A cylinder separated the cone and the flare and acted as an isolator to reduce the influence of the SWBLI experiment on the BLT experiment. A lot of ground tests preceded the flight tests ${ }^{4-6}$, but as the nominal flight angle of attack was zero none of them were performed at angles of attack higher than $6^{\circ}$.

During the flight of HIFiRE-1 in March 2010 the exoatmospheric pointing maneuver differed from the original plan, which caused the vehicle to enter the atmosphere with an angle of attack as high as $40^{\circ}$. Although the angle of attack oscillations damped and decreased, the payload was still at over $10^{\circ}$ angle of attack as aerothermal data began to be collected. The HIFiRE-1 flight test reached $M a \in[6.8,7.4]$ during descent, while the descent freestream unit Reynolds number steadily increased from 2 to $40 \cdot 10^{6} \frac{1}{\mathrm{~m}}{ }^{7-9}$. Even though the angle of attack during the relevant portion of the flight is known, it is impossible to separate the effect of angle of attack from Reynolds number. Therefore, additional wind tunnel tests at high angle of attack and high Reynolds number were necessary for the flight data analysis.

\section{Experiment set-up}

\section{II.A. Model}

To match the boundary-layer transition experiment of HIFiRE-1, the basic model shape is a $7^{\circ}$ half angle cone. The model consists of three exchangeable segments - the apex, the middle segment and the rear segment and is supported by a central steel shaft (see figure 1). The middle and the rear segment are made of PEEK (polyether ether ketone) to allow infrared thermography. Two steel apexes were used with nose radii of $r=2.5 \mathrm{~mm}$ for a full-scale match of HIFiRE- 1 and $r=1.6 \mathrm{~mm}$ to match the ratio of nose radius to model length. The base radius is $90 \mathrm{~mm}$, therefore the model length is either $715.0 \mathrm{~mm}$ or $721.5 \mathrm{~mm}$.

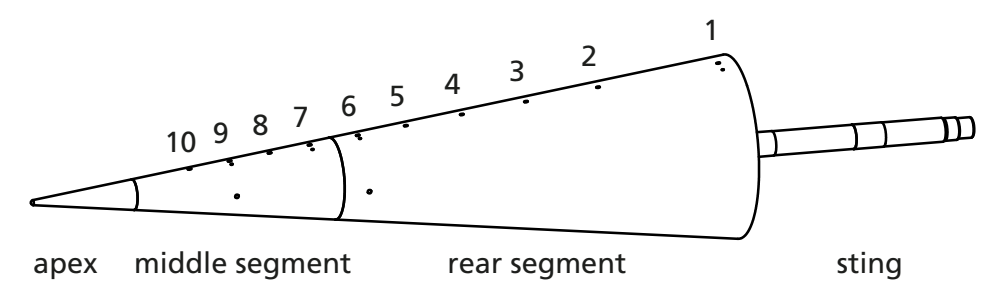

Figure 1. Drawing of the model with segments and marked sensor positions

\section{II.B. Wind tunnel}

The experiments were performed in the hypersonic wind tunnel Cologne (H2K). It is a blow-down wind tunnel with a free jet test section and a test time of $30 \mathrm{~s}$ (figure 2a). For the experiments a Mach 7 contoured nozzle with an exit diameter of $600 \mathrm{~mm}$ was used. The test gas air is heated with resistance heaters. Figure $2 \mathrm{~b}$ 
shows the test section with the model. For further information about the H2K see Niezgodka ${ }^{10}$. The nominal inflow conditions used for the experiments are listed in table 1.

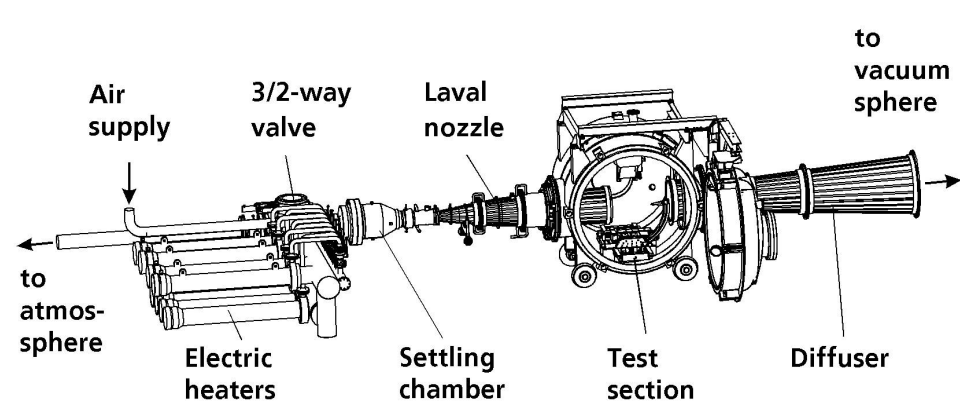

(a) Sketch of $\mathrm{H} 2 \mathrm{~K}$

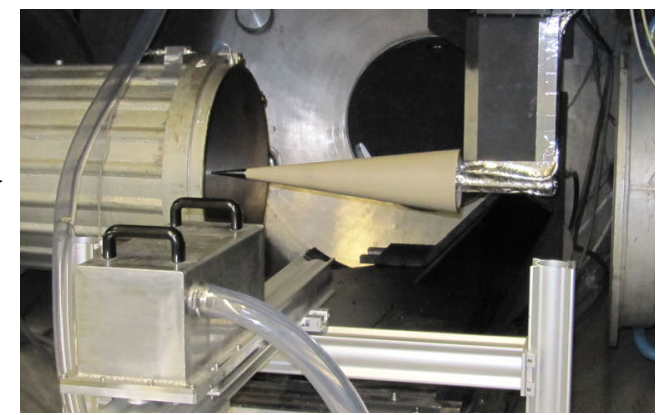

(b) model inside the test section

Figure 2. The hypersonic wind tunnel Cologne (H2K)

Table 1. Nominal inflow conditions for the tests in $\mathrm{H} 2 \mathrm{~K}$

\begin{tabular}{cccccc}
\hline$M a[]$ & $T_{0}[\mathrm{~K}]$ & $p_{0}[\mathrm{kPa}]$ & $T_{\infty}[\mathrm{K}]$ & $p_{\infty}[\mathrm{Pa}]$ & $R e_{u, \infty}\left[\frac{1}{\mathrm{~m}}\right]$ \\
\hline 7.10 & 600 & 2790 & 56 & 674 & $11.5 \cdot 10^{6}$ \\
7.08 & 600 & 2300 & 56 & 556 & $9.5 \cdot 10^{6}$ \\
7.06 & 600 & 1820 & 56 & 440 & $7.5 \cdot 10^{6}$ \\
7.04 & 600 & 1330 & 56 & 321 & $5.5 \cdot 10^{6}$ \\
\hline
\end{tabular}

\section{II.C. Instrumentation}

The surface temperature on the PEEK segments is captured via two infrared cameras. The top view is captured with an Infratec ImageIR 8300 at a sample rate of $80 \mathrm{~Hz}$ and a resolution of $640 \times 512$ Pixel. Due to the position of the window and the viewing angle of the camera the first $40 \mathrm{~mm}$ of the middle segment are not visible in the top view. In addition the view onto the rear segment is partly blocked by the mounting device for $\alpha \leq-9^{\circ}$. The side view is captured with a FLIR ${ }^{\circledR}$ SC3000 at $60 \mathrm{~Hz}$ and a resolution of $320 \times 240$ Pixel. In the side view always the complete PEEK segments are visible. The model is equipped with four Kulite ${ }^{\circledR}$ XCQ-080 sensors with a $35 \mathrm{kPa}$ range and a natural frequency of $150 \mathrm{kHz}$ for static and low speed surface pressure measurements. They are connected to a NI PXIe-4331 bridge module. For high speed pressure measurements the model is equipped with sixteen $\mathrm{PCB}^{\circledR} 132 \mathrm{~A} 31$ sensors with a $350 \mathrm{kPa}$ range and a resonant frequency above $1 \mathrm{MHz}$. They are connected to signal conditioners $\mathrm{PCB}{ }^{\circledR} 482 \mathrm{C} 05$ and their output signals are measured with Adlink PXI-9816D/512 digitizers. Ten of the PCB sensors are placed on a generatrix numbered according to figure 1 from the base to the apex. At two positions (6 and 9$)$ there are four PCB spaces around the circumference. The Kulite sensors are placed close to the PCB 1,6, 7 and 9.

The used coordinate system has its origin at the theoretic tip of a perfect sharp cone with the x-axis pointing in flow direction and the z-axis to the top of the test section. The angle $\Phi$ used for cylindrical coordinates around the $\mathrm{x}$-axis is defined such that $0^{\circ}$ is the windward ray and $180^{\circ}$ the lee side ray.

\section{II.D. Data processing}

The raw data of the infrared camera are transferred to heat fluxes and Stanton numbers using the in-house tool VisualHeatFlow (for the algorithm see Henckels and Gruhn ${ }^{11}$ ). The recovery factor for the postprocessing of the infrared images is always set to the value of a laminar boundary layer $\sqrt{P r}=\sqrt{0.73}$. For the surface plots in cylindrical coordinates the images of the infrared cameras are interpolated onto a 3D CAD model of the cone. The information of the full $360^{\circ}$ are taken from four videos that are videos of both cameras at two runs at the same angle of attack but opposite sign.

The averaged frequency spectra, shown in this paper, are based on twenty-five-million data points at stable flow conditions (5 $@ 5 \mathrm{MHz}$ ) divided into 1000 blocks with 50000 samples each. The blocks overlap 
Table 2. Sensor positions given by the local model radius $r$ as well as the x-coordinate and the path length $s$ measured from the nose tip for different nose radii

\begin{tabular}{cccccccc} 
& \multicolumn{3}{c}{$r_{N}=0.0 \mathrm{~mm}$} & \multicolumn{2}{c}{$r_{N}=1.6 \mathrm{~mm}$} & \multicolumn{2}{c}{$r_{N}=2.5 \mathrm{~mm}$} \\
No. & $r[\mathrm{~mm}]$ & $x[\mathrm{~mm}]$ & $s[\mathrm{~mm}]$ & $x[\mathrm{~mm}]$ & $s[\mathrm{~mm}]$ & $x[\mathrm{~mm}]$ & $s[\mathrm{~mm}]$ \\
\hline parting & 15.0 & 122.2 & 123.1 & 110.6 & 112.4 & 104.2 & 106.3 \\
\hline 10 & 22.0 & 179.2 & 180.5 & 167.6 & 169.8 & 161.2 & 163.8 \\
9 & 27.0 & 219.9 & 221.5 & 208.4 & 210.8 & 201.9 & 204.8 \\
8 & 32.0 & 260.6 & 262.6 & 249.1 & 251.9 & 242.6 & 245.8 \\
7 & 37.0 & 301.3 & 303.6 & 289.8 & 292.9 & 283.3 & 286.9 \\
\hline parting & 40.0 & 325.8 & 328.2 & 314.2 & 317.5 & 307.8 & 311.5 \\
\hline 6 & 43.0 & 350.2 & 352.8 & 338.7 & 342.1 & 332.2 & 336.1 \\
5 & 49.0 & 399.1 & 402.1 & 387.5 & 391.4 & 381.1 & 385.3 \\
4 & 56.0 & 456.1 & 459.5 & 444.6 & 448.8 & 438.1 & 442.8 \\
3 & 64.0 & 521.2 & 525.2 & 509.7 & 514.4 & 503.2 & 508.4 \\
2 & 73.0 & 594.5 & 599.0 & 583.0 & 588.3 & 576.5 & 582.3 \\
1 & 88.0 & 716.7 & 722.1 & 705.2 & 711.4 & 698.7 & 705.3 \\
\hline base & 90.0 & 733.0 & 738.5 & 721.5 & 727.8 & 715.0 & 721.8 \\
\hline
\end{tabular}

each other by $50 \%$. All values are normalized with static pressure of the inflow and then each block is multiplied with the Hann function. For each block the power spectral density is computed. The arithmetic mean of all spectra is the final result. Hence the frequency spectra show root mean square values scaled with the frequency.

\section{Results}

In the first experiments the yaw angle and the pitch angle were adjusted until the measured surface temperature distribution was symmetric from the side and from the top. Thus the model was precisely aligned at zero angle of attack within $0.3^{\circ}$. Figures $3,8,9,11,12,14,15,17$ and 18 show the surface temperatures of the model after $10 \mathrm{~s}$ of steady flow conditions with $R e_{u, \infty} \approx 9.4 \cdot 10^{6} \frac{1}{\mathrm{~m}}$ for different angles of attack in the original perspective view of the cameras. Figures 4, 10, 13, 16 and 19 show the corresponding Stanton number distributions on the cone surface in cylindrical coordinates.

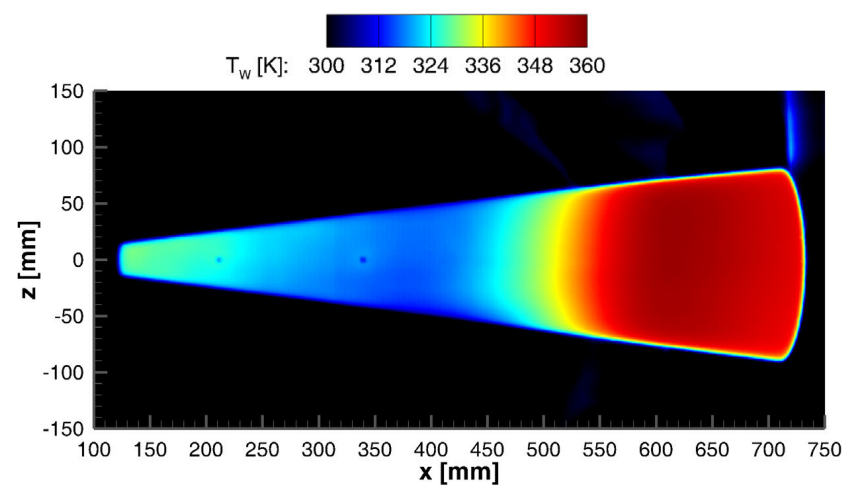

(a) side view

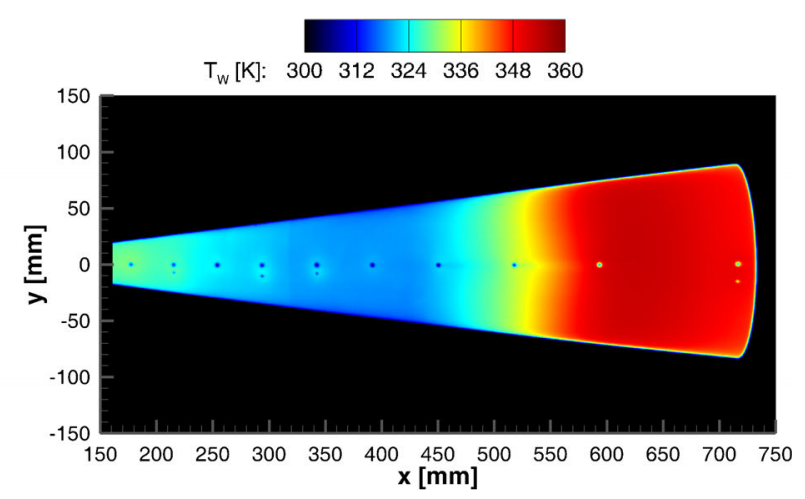

(b) top view

Figure 3. Surface temperatures during run 4: $R e_{u, \infty}=9.28 \cdot 10^{6} \frac{1}{\mathrm{~m}}, T_{0}=600.9 \mathrm{~K}, p_{0}=2330 \mathrm{kPa}, r_{N}=1.6 \mathrm{~mm}, \alpha=0^{\circ}$

At zero angle of attack (figures 3 and 4 ) the isothermal lines are almost straight and perpendicular with the model axis. The transition onset is approximately at $x=480 \mathrm{~mm}$ and the transition end at $x=600 \mathrm{~mm}$. This is in good agreement with the occurrence, amplification and destruction of the second (Mack) mode visible in the averaged spectra of the PCB measurements at different locations in flow direction plotted in 
figure 5. The frequency of the second (Mack) mode at the transition onset is about $300 \mathrm{kHz}$ and decreases to $200 \mathrm{kHz}$ at the transition end.

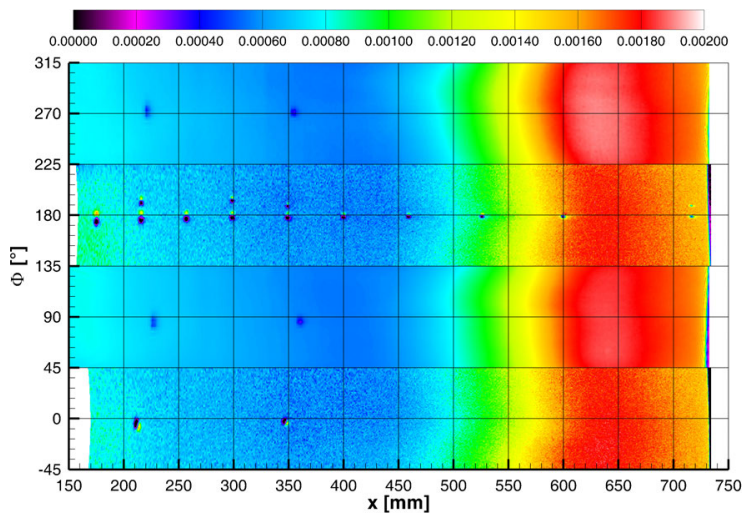

Figure 4. Stanton numbers on the cone surface during run 4 and 12 with $\alpha=0^{\circ}$

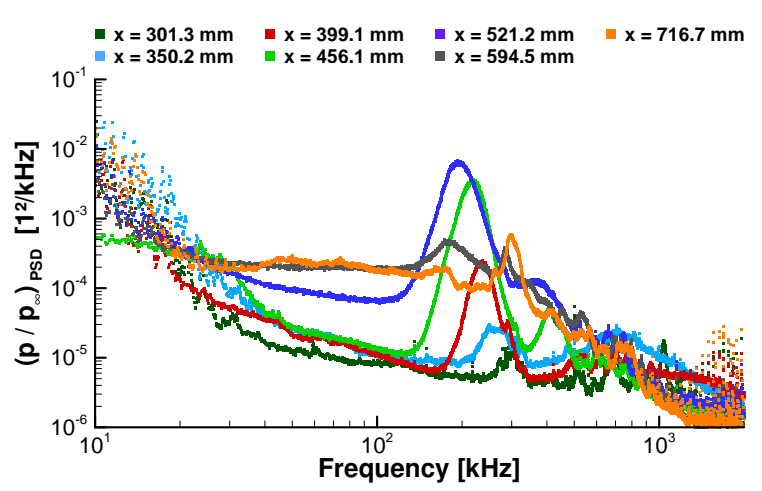

Figure 5. Spectra of PCB measurements during run 4: $R e_{u, \infty}=9.28 \cdot 10^{6} \frac{1}{\mathrm{~m}}, T_{0}=600.9 \mathrm{~K}, p_{0}=2330 \mathrm{kPa}, r_{N}=$ $1.6 \mathrm{~mm}, \alpha=0^{\circ}$

Figure 8 shows the surface temperatures for $\alpha=6^{\circ}$ and figure 9 for $\alpha=-6^{\circ}$. The corresponding Stanton numbers in cylindrical coordinates are plotted in figure 10. The significant temperature and Stanton number increase, which indicates the transition position, moves upstream on the lee side $\left(135^{\circ}<\Phi<225^{\circ}\right)$ and downstream on the windward side $\left(-45^{\circ}<\Phi<45^{\circ}\right)$. The transition onset is approximately at $x=250 \mathrm{~mm}$ on the lee side ray and at $x=570 \mathrm{~mm}$ on the windward ray. But the maximum temperatures and Stanton numbers are much higher on the windward side. Transition is significantly further upstream close to the symmetry plane on the lee side $\left(160^{\circ}<\Phi<200^{\circ}\right)$. On both sides of the symmetry plane are some streaky structures almost parallel to the $\mathrm{x}$-axis in the perspective image figure $8 \mathrm{~b}$ but clearly pointing towards the symmetry plane in cylindrical coordinates figure 10 . At the yaw sides $\left(45^{\circ}<\Phi<135^{\circ}\right.$ and $\left.225^{\circ}<\Phi<315^{\circ}\right)$ the transition onset moves upstream, the furthest at $\Phi=90^{\circ}$ and $\Phi=270^{\circ}$ to $x=380 \mathrm{~mm}$. Hence, the shift is not as high as on the lee side ray. There are streaky structures visible inside the transition region an the maximum Stanton numbers increase towards the windward side.

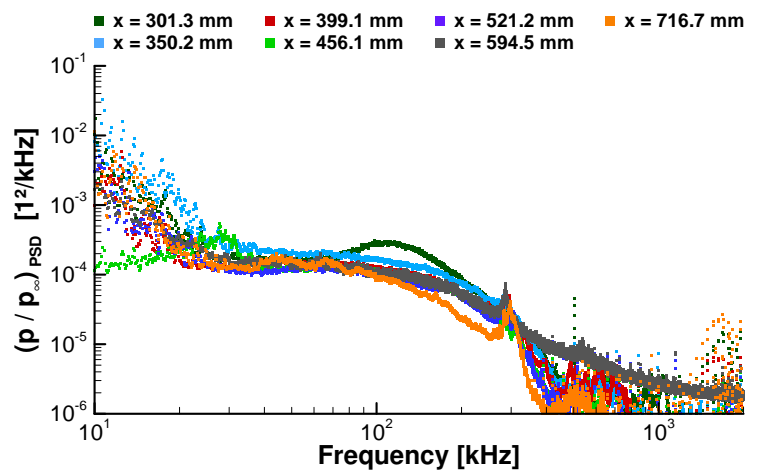

Figure 6. Spectra of PCB measurements during run 5: $R e_{u, \infty}=9.24 \cdot 10^{6} \frac{1}{\mathrm{~m}}, T_{0}=599.8 \mathrm{~K}, p_{0}=2314 \mathrm{kPa}, r_{N}=$ $1.6 \mathrm{~mm}, \alpha=6^{\circ}$ (leeward ray)

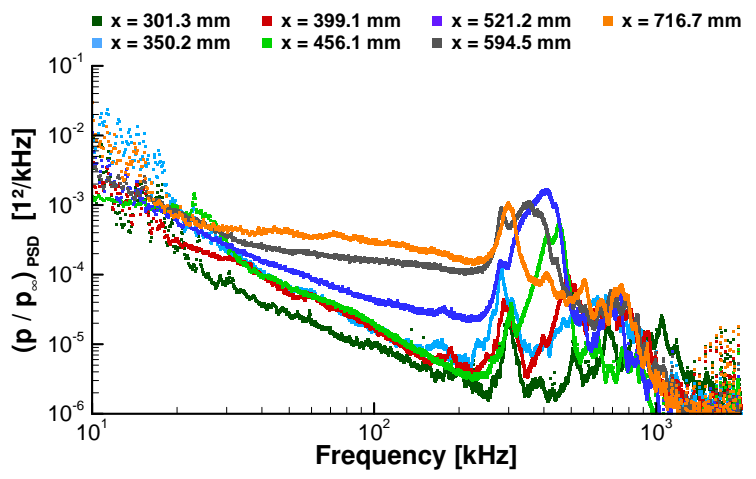

Figure 7. Spectra of PCB measurements during run 8: $R e_{u, \infty}=9.11 \cdot 10^{6} \frac{1}{\mathrm{~m}}, T_{0}=601.4 \mathrm{~K}, p_{0}=2288 \mathrm{kPa}, r_{N}=$ $1.6 \mathrm{~mm}, \alpha=-6^{\circ}$ (windward ray)

The upstream shift of the transition position on the leeward ray and the downstream shift on the windward ray are also visible in the PCB spectra. On the leeward ray (figure 6) the PCB sensor at $x=301.2 \mathrm{~mm}$ registers the remains of the second (Mack) mode at a frequency of about $100 \mathrm{kHz}$. All sensors downstream register the broad band spectrum of a turbulent boundary layer. On the windward ray (figure 7) the second (Mack) mode occurs downstream compared to the leeward ray and the cone at $\alpha=0^{\circ}$ and the frequencies are above $300 \mathrm{kHz}$. For detailed analysis of the PCB data refer to Juliano et al. ${ }^{1}$.

The situation for $\alpha= \pm 9^{\circ}$ is shown in the figures 11 and 12 and figure 13 respectively. On the symmetry axis of the windward side the transition is delayed towards the end of the model. The transition onset is approximately at $x=670 \mathrm{~mm}$. There are also some slight streaky structures pointing from the centerline outwards (just visible in the raw image figure 12a). Right from the start there is is a narrow band of increased 


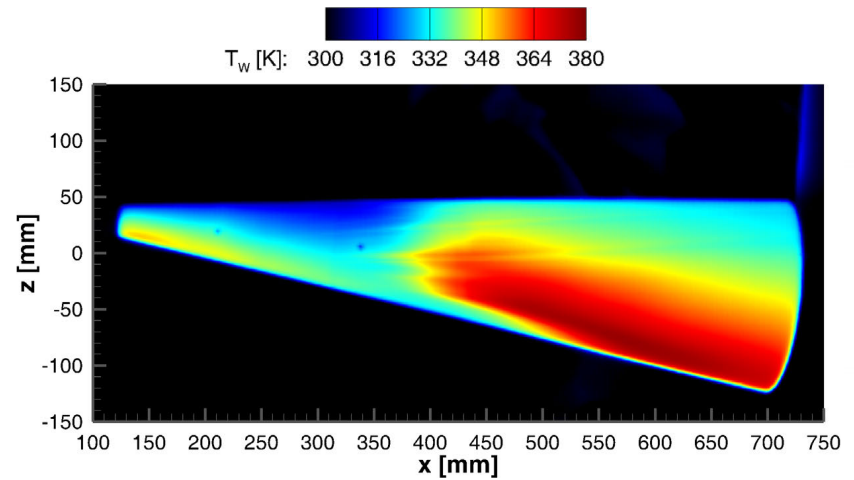

(a) side view

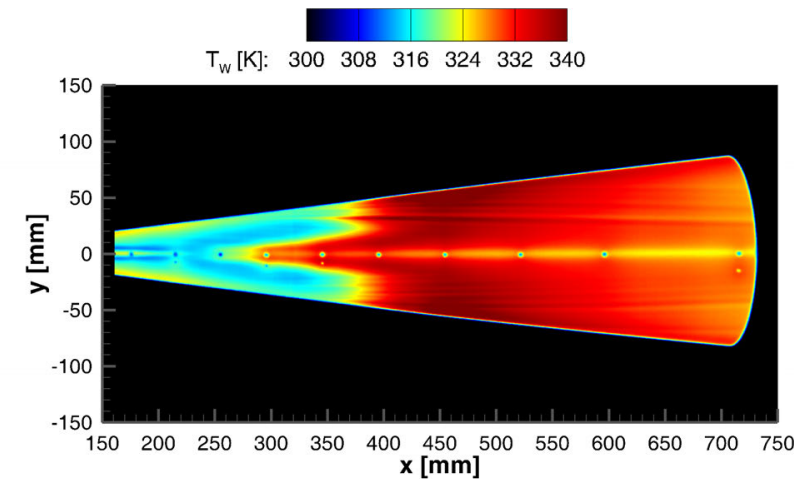

(b) top view

Figure 8. Surface temperatures during run 5: $R e_{u, \infty}=9.24 \cdot 10^{6} \frac{1}{\mathrm{~m}}, T_{0}=599.8 \mathrm{~K}, p_{0}=2314 \mathrm{kPa}, r_{N}=1.6 \mathrm{~mm}, \alpha=6^{\circ}$

$\begin{array}{lllllll}T_{w}[\mathrm{~K}] & 300 & 316 & 332 & 348 & 364 & 380\end{array}$

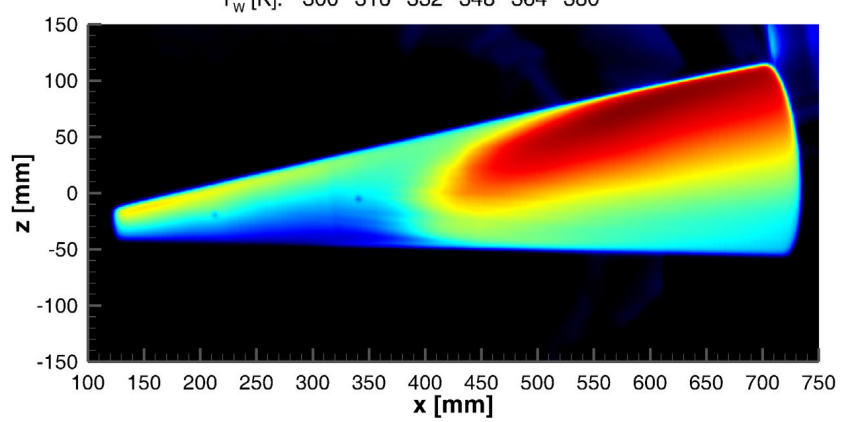

(a) side view

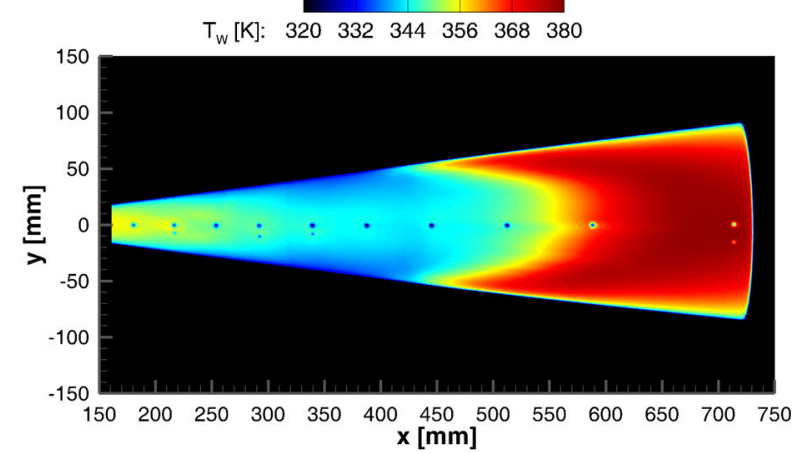

(b) top view

Figure 9. Surface temperatures during run 8: $R e_{u, \infty}=9.11 \cdot 10^{6} \frac{1}{\mathrm{~m}}, T_{0}=601.4 \mathrm{~K}, p_{0}=2288 \mathrm{kPa}, r_{N}=1.6 \mathrm{~mm}, \alpha=-6^{\circ}$

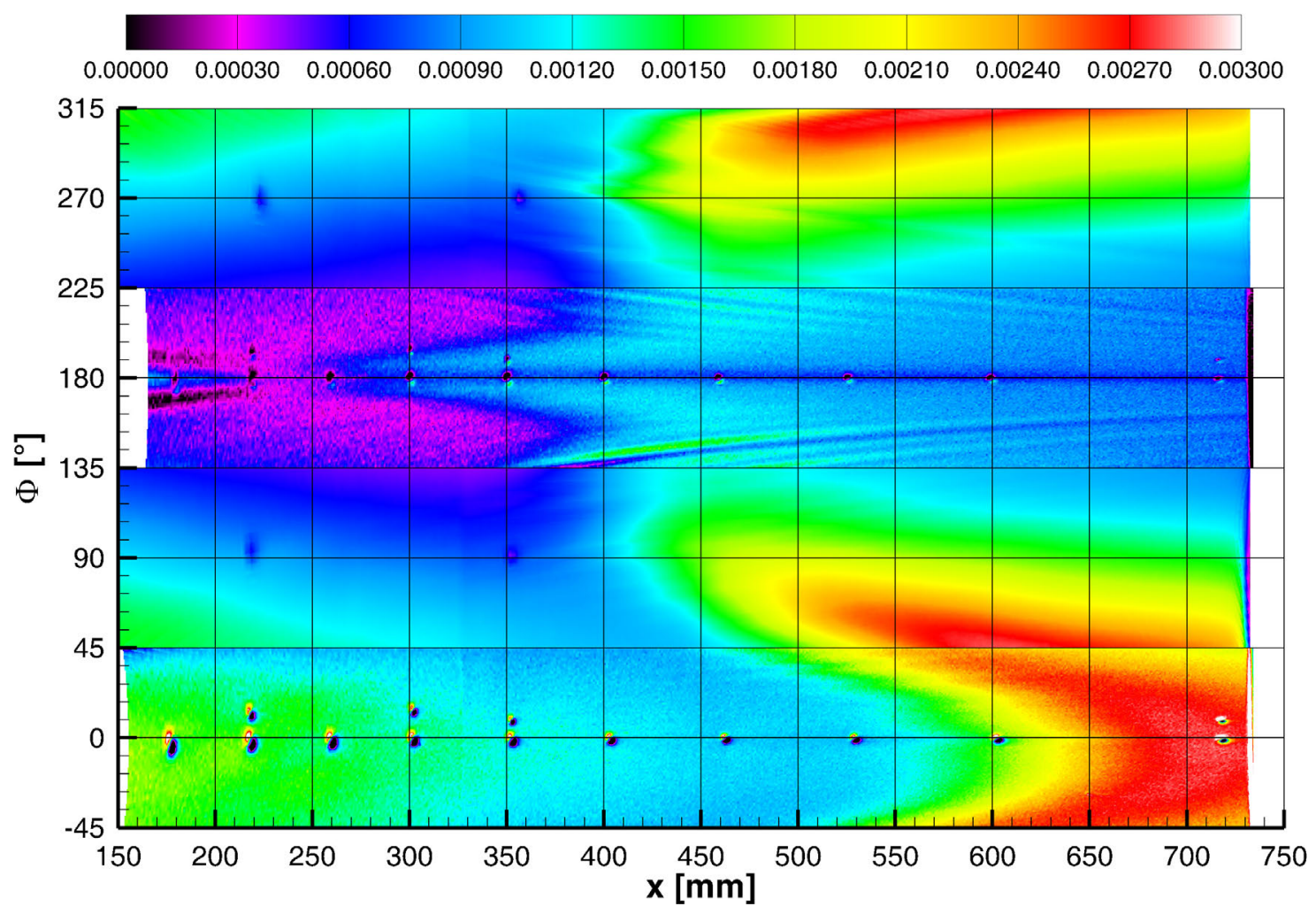

Figure 10. Stanton numbers on the cone surface during run 5 and 8 with $\alpha=6^{\circ}$ 


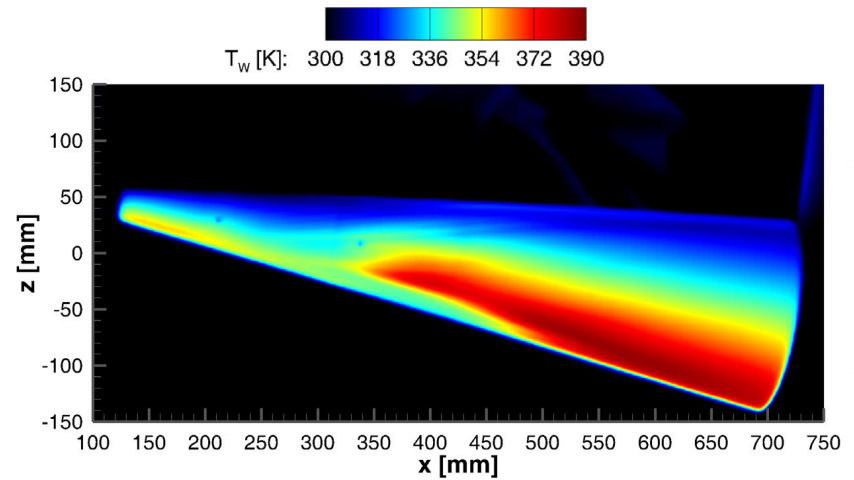

(a) side view

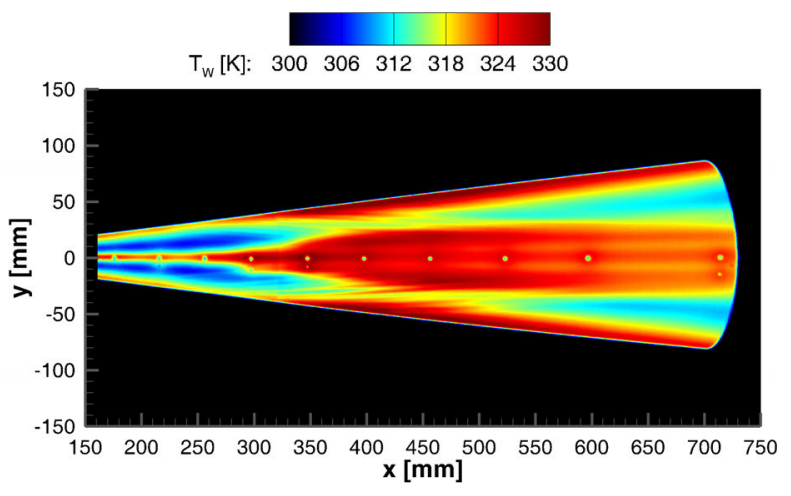

(b) top view

Figure 11. Surface temperatures during run 6: $R e_{u, \infty}=9.09 \cdot 10^{6} \frac{1}{\mathrm{~m}}, T_{0}=601.4 \mathrm{~K}, p_{0}=2284 \mathrm{kPa}, r_{N}=1.6 \mathrm{~mm}, \alpha=9^{\circ}$

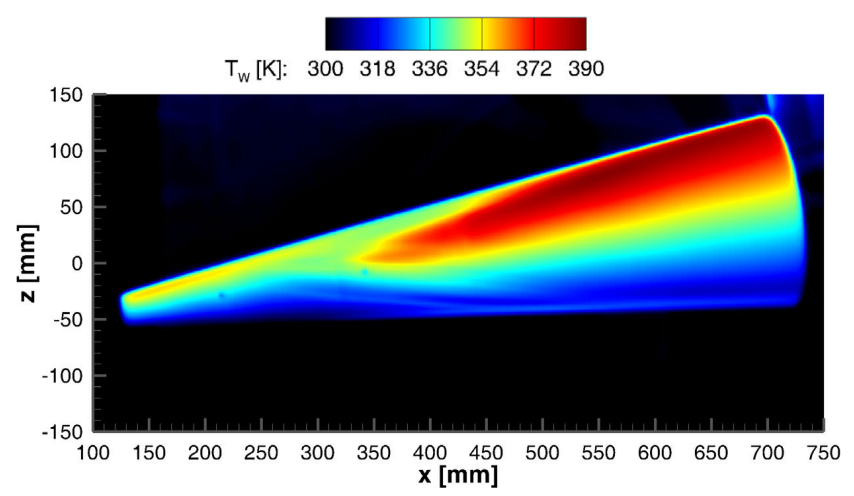

(a) side view

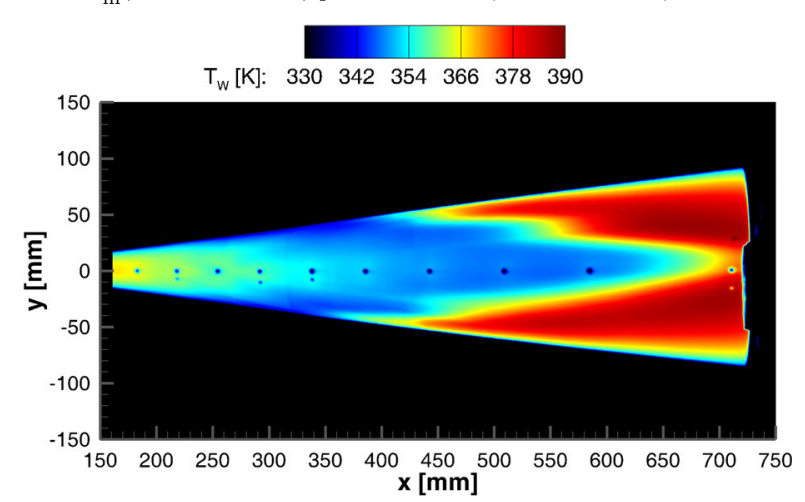

(b) top view

Figure 12. Surface temperatures during run 9: $R e_{u, \infty}=9.14 \cdot 10^{6} \frac{1}{\mathrm{~m}}, T_{0}=600.6 \mathrm{~K}, p_{0}=2293 \mathrm{kPa}, r_{N}=1.6 \mathrm{~mm}, \alpha=-9^{\circ}$

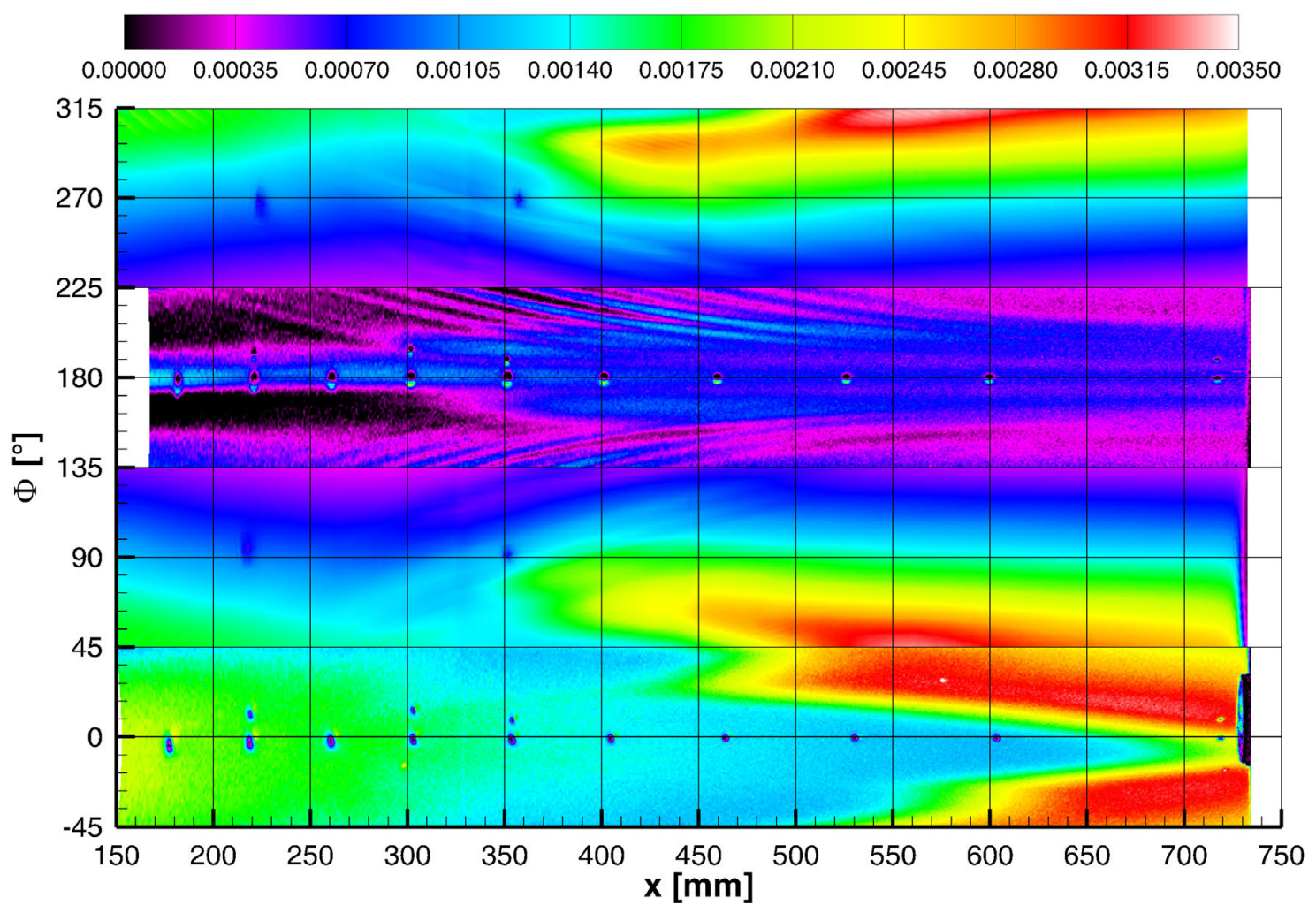

Figure 13. Stanton numbers on the cone surface during run 6 and 9 with $\alpha=9^{\circ}$ 


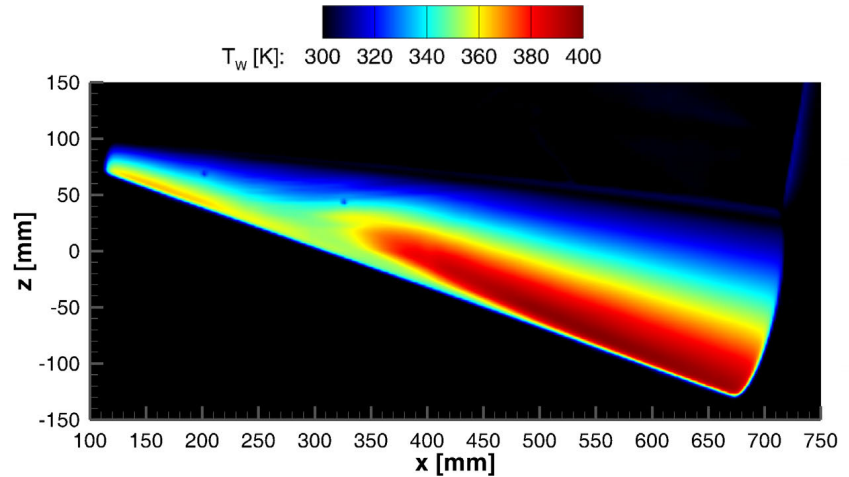

(a) side view

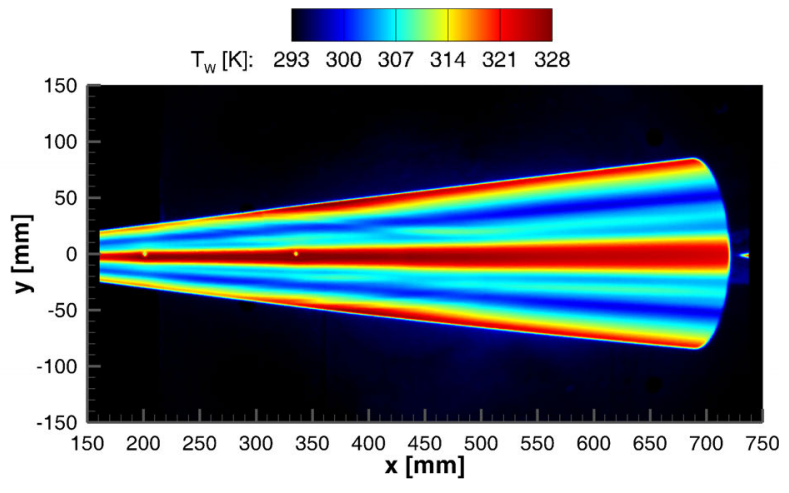

(b) top view

Figure 14. Surface temperatures during run 14: $R e_{u, \infty}=9.37 \cdot 10^{6} \frac{1}{\mathrm{~m}}, T_{0}=601.1 \mathrm{~K}, p_{0}=2354 \mathrm{kPa}, r_{N}=1.6 \mathrm{~mm}, \alpha=12^{\circ}$

$T_{\text {[ }}[\mathrm{K}]: \begin{array}{lllllll}300 & 320 & 340 & 360 & 380 & 400\end{array}$

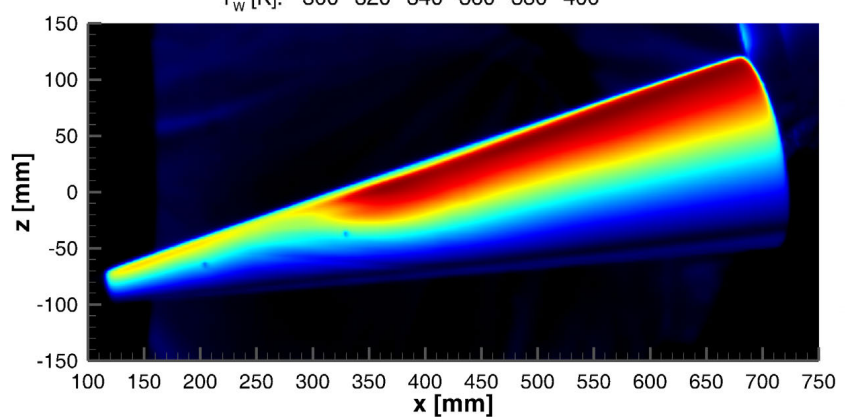

(a) side view

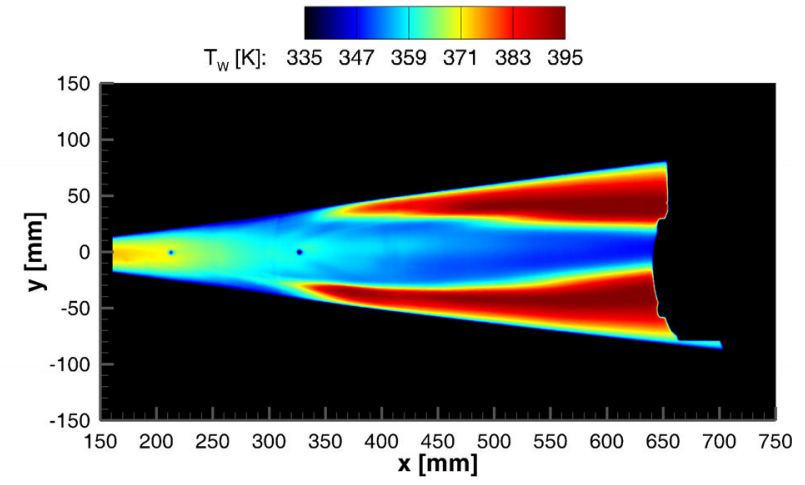

(b) top view

Figure 15. Surface temperatures during run 17: $R e_{u, \infty}=9.59 \cdot 10^{6} \frac{1}{\mathrm{~m}}, T_{0}=601.6 \mathrm{~K}, p_{0}=2413 \mathrm{kPa}, r_{N}=1.6 \mathrm{~mm}, \alpha=-12^{\circ}$

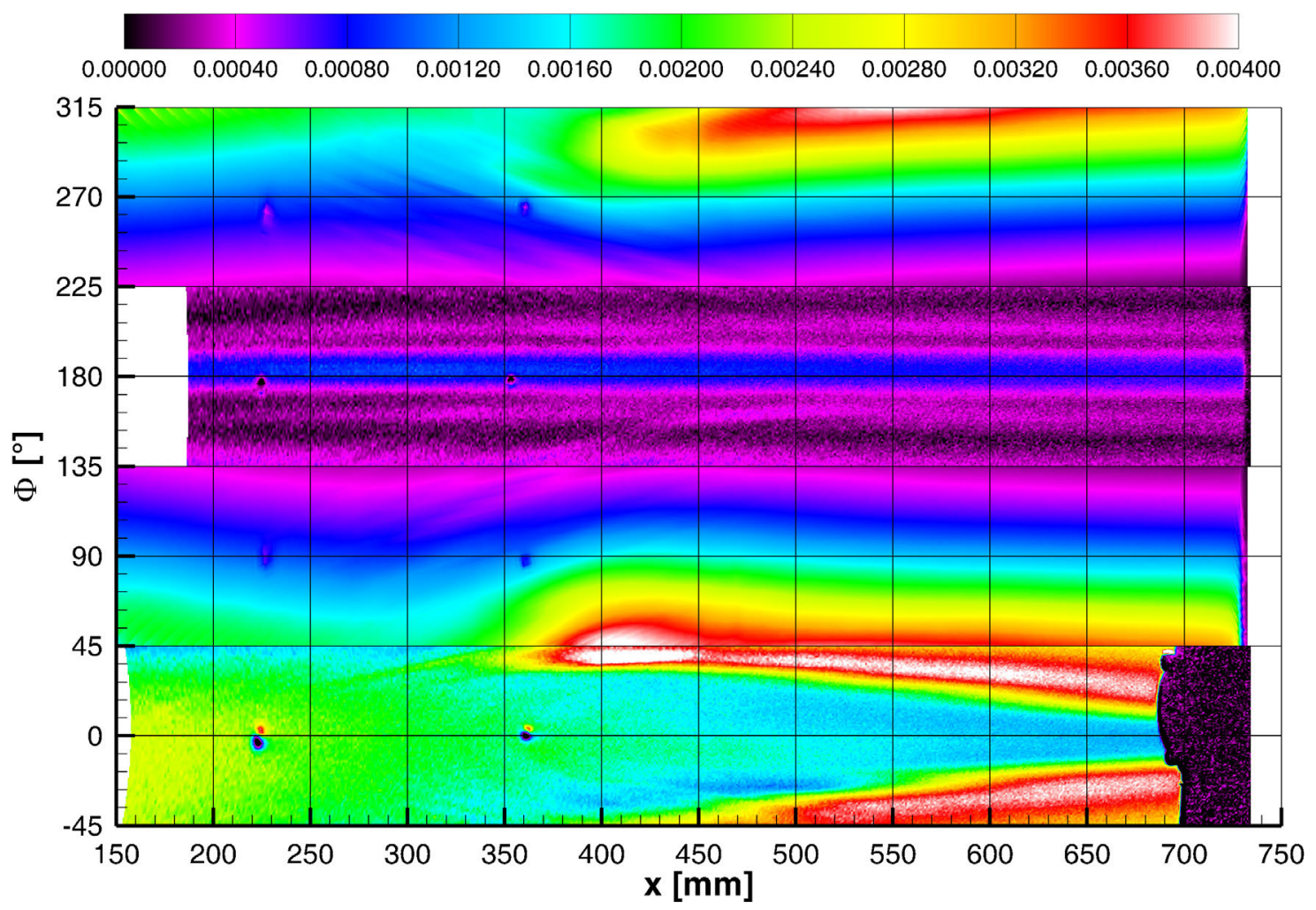

Figure 16. Stanton numbers on the cone surface during run 14 and 17 with $\alpha=12^{\circ}$ 


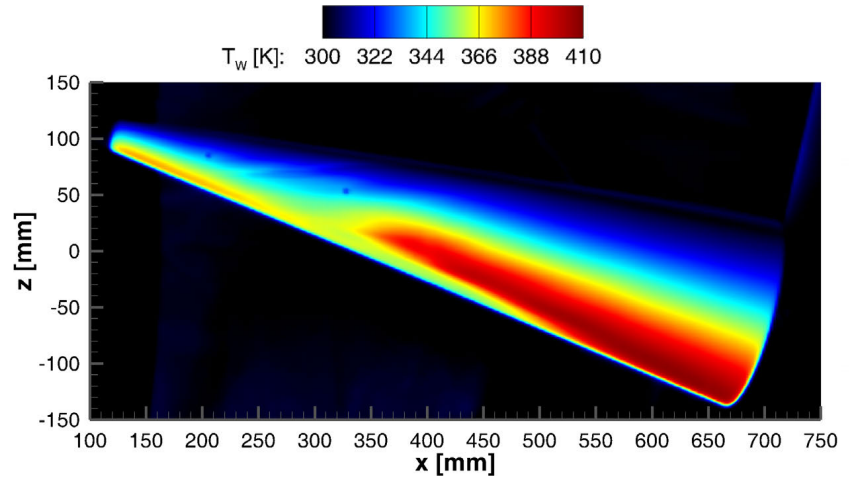

(a) side view

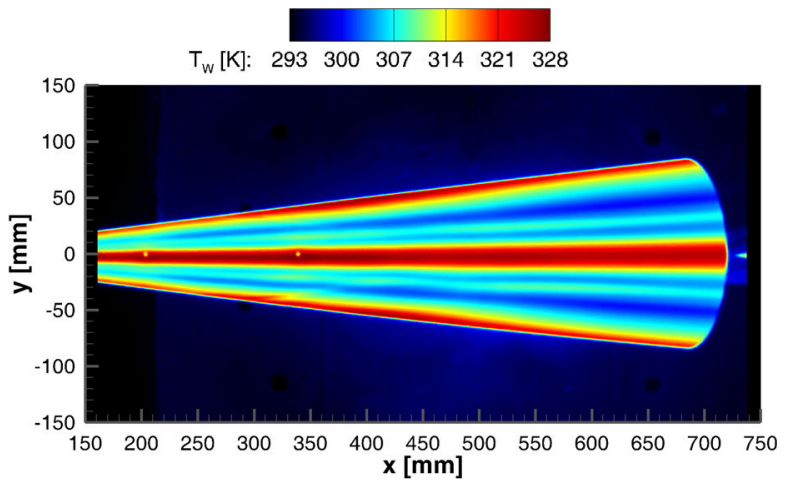

(b) top view

Figure 17. Surface temperatures during run 15: $R e_{u, \infty}=9.05 \cdot 10^{6} \frac{1}{\mathrm{~m}}, T_{0}=605.0 \mathrm{~K}, p_{0}=2295 \mathrm{kPa}, r_{N}=1.6 \mathrm{~mm}, \alpha=15^{\circ}$

$T_{w}[\mathrm{~K}]: \begin{array}{llllll}300 & 322 & 344 & 366 & 388 & 410\end{array}$

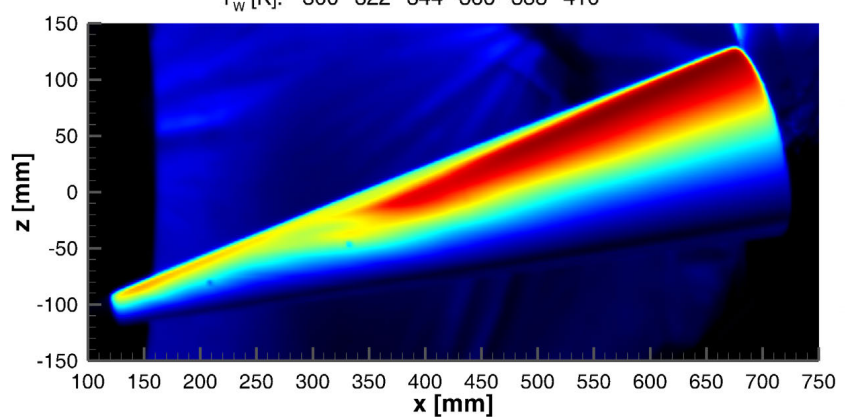

(a) side view

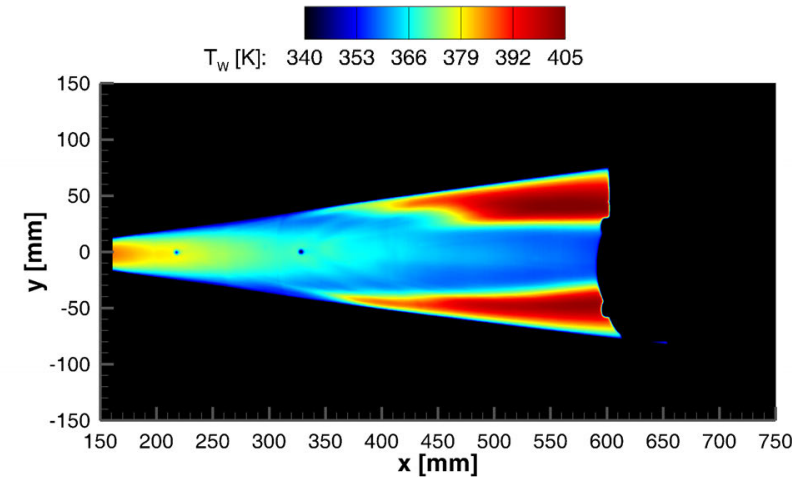

(b) top view

Figure 18. Surface temperatures during run 18: $R e_{u, \infty}=9.26 \cdot 10^{6} \frac{1}{\mathrm{~m}}, T_{0}=604.9 \mathrm{~K}, p_{0}=2349 \mathrm{kPa}, r_{N}=1.6 \mathrm{~mm}, \alpha=-15^{\circ}$

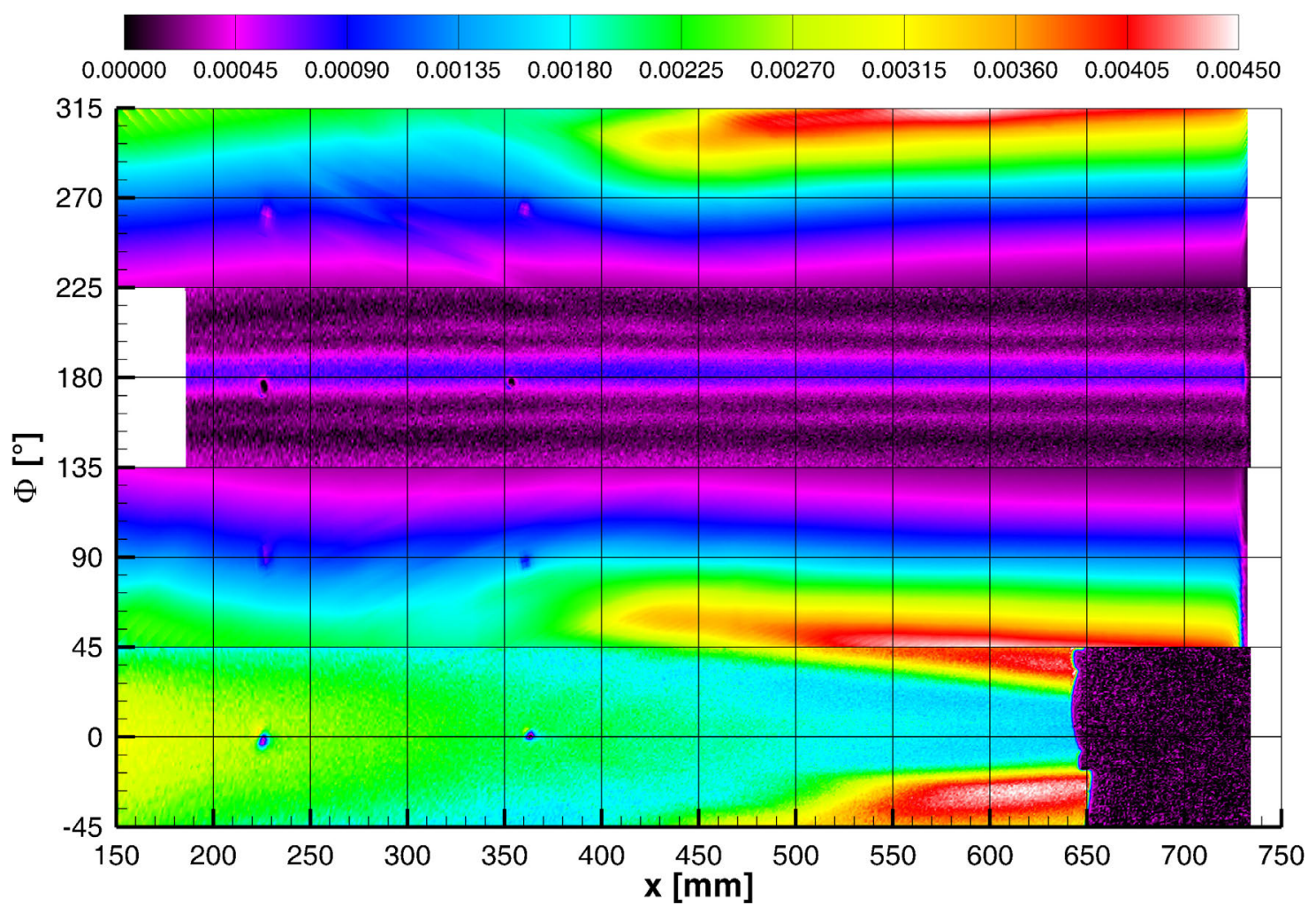

Figure 19. Stanton numbers on the cone surface during run 15 and 18 with $\alpha=15^{\circ}$ 
surface temperature and Stanton number on the symmetry axis of the lee side $\left(174^{\circ}<\Phi<186^{\circ}\right)$. Again there are streaky structures inclined toward the leeward centerline. The region of increased temperature widens where the streaks reach the symmetry plane $(x=350 \mathrm{~mm})$, but the turbulent region never extends beyond $20^{\circ}$ from the leeward symmetry plane. Between the symmetry axis and the yaw sides are regions with no clear transition $\left(130^{\circ}<\Phi<160^{\circ}\right.$ and $\left.205^{\circ}<\Phi<230^{\circ}\right)$. At the yaw sides the earliest transition onsets are at $\Phi=75^{\circ}$ and $\Phi=295^{\circ}$ and $x=330 \mathrm{~mm}$. Hence, these points moved upstream and towards the windward side compared to $\alpha=6^{\circ}$. Again there are streaky structures visible inside the transition region an the maximum Stanton numbers increase towards the windward side.

The observed trends continue for $\alpha= \pm 12^{\circ}$ in figures 14 to 16 and $\alpha= \pm 15^{\circ}$ in figures 17 to 19 . There is no temperature increase on the windward ray (at least until the model mount blocks the view); hence, the boundary layer probably stays completely laminar there. The outwards pointing streaky structures become more distinct. Towards the borders there are regions with a significant temperature and Stanton number increase which are probably caused by a boundary layer transition. On the lee side there is a narrow region of increased temperature and Stanton number from the tip to the base that suggests a turbulent boundary layer. On both sides of this band is another streak visible but at a much lower level. There is now significant increase in the streamwise direction that would indicate a transition region on the lee side. The earliest transition onsets on the yaw sides are close to $\Phi=45^{\circ}$ and $\Phi=315^{\circ}$. There are streaky structures visible on the yaw sides but they are before the transition regions.

\section{Discussion and Conclusions}

For the post-flight analysis of HIFiRE-1 a test campaign was carried out in the in the hypersonic wind tunnel H2K. The boundary-layer transition experiments on the $7^{\circ}$ half angle cone were performed at Mach 7 , high angles of attack $\left(0^{\circ} \leq \alpha \leq 15^{\circ}\right)$ and high Reynolds numbers $\left(5.5 \cdot 10^{6} \frac{1}{\mathrm{~m}} \leq R e_{u, \infty} \leq 11.5 \cdot 10^{6} \frac{1}{\mathrm{~m}}\right)$. The gathered data are valuable for a better understanding of the flight data at high angles of attack.

The heat flux measurements based on quantitative infrared thermography show clearly the delayed transition on the windward side for $0^{\circ}<\alpha \leq 9^{\circ}$. For $\alpha \geq 12^{\circ}$ the boundary layer stays laminar along the complete windward ray. There are distinct streaks from the windward side towards the lee side, which is an indication for arising crossflow vortices. At moderate angles of attack $\left(0^{\circ}<\alpha<9^{\circ}\right)$ an early transition can be identified on the lee side of the model. A significant earlier transition on the lee side ray is probably caused by the counter rotating vortices from both sides of the model which interact in the symmetry plane. For high angles of attack $\left(\alpha>9^{\circ}\right)$ the definite transition regions on the lee side disappear. There the surface temperature suggests that the boundary layer on the centerline becomes turbulent shortly after the tip of the cone but stays laminar at the sides. The single streaks on both sides of the leeward side might be the foot print of large vortices. The transition region also moves upstream on the yaw sides and the earliest transition onsets are closer to the windward side for higher angles of attack.

\section{Acknowledgments}

This research was performed while Dr. Juliano held a National Research Council Research Associateship Award. The great effort and support of the H2K operation team (Michael Kosbow and Marco Schmors) is gratefully acknowledged.

\section{References}

1 Juliano, T. J., Kimmel, R. L., Willems, S., Gülhan, A., and Schneider, S. P., "Surface Pressure Fluctuation Measurements from High Reynolds, High Angle HiFIRE-1 Ground Test," SciTech, American Institute of Aeronautics and Astronautics, 2014.

${ }^{2}$ Dolvin, D. J., "Hypersonic International Flight Research and Experimentation (HIFiRE) - Fundamental Sciences and Technology Development Strategy," 15th AIAA International Space Planes and Hypersonic Systems and Technologies Conference, American Institute of Aeronautics and Astronautics, Dayton, Ohio, 2008.

${ }^{3}$ Dolvin, D. J., "Hypersonic International Flight Research and Experimentation Technology Development 
and Flight Certification Strategy," 16th AIAA/DLR/DGLR International Space Planes and Hypersonic Systems and Technologies Conference, American Institute of Aeronautics and Astronautics, Bremen, 2009 .

${ }^{4}$ Berger, K. T., Greene, F. a., Kimmel, R., Alba, C., and Johnson, H., "Aerothermodynamic Testing and Boundary-Layer Trip Sizing of the HIFiRE Flight 1 Vehicle," Journal of Spacecraft and Rockets, Vol. 45, No. 6, Nov. 2008, pp. 1117-1124.

5 Casper, K. M., Johnson, H. B., and Schneider, S. P., "Effect of Freestream Noise on Roughness-Induced Transition for a Slender Cone," Journal of Spacecraft and Rockets, Vol. 48, No. 3, May 2011, pp. 406-413.

6 Wadhams, T. P., Mundy, E., MacLean, M. G., and Holden, M. S., "Ground Test Studies of the HIFiRE-1 Transition Experiment Part 1: Experimental Results," Journal of Spacecraft and Rockets, Vol. 45, No. 6, Nov. 2008, pp. 1134-1148.

7 Adamczak, D. and Kimmel, R. L., "HIFiRE-1 Flight Trajectory Estimation and Initial Experimental Results," 17th AIAA International Space Planes and Hypersonic Systems and Technologies Conference, No. April, American Institute of Aeronautics and Astronautics, San Francisco, 2011, pp. 1-13.

8 Kimmel, R. L. and Adamczak, D., "HIFiRE-1 Preliminary Aerothermodynamic Measurements," 41st AIAA Fluid Dynamics Conference and Exhibit, No. June, American Institute of Aeronautics and Astronautics, Honolulu, Hawaii, 2011.

9 Kimmel, R. L. and Adamczak, D., "HIFiRE-1 Background and Lessons Learned," 50th AIAA Aerospace Sciences Meeting including the New Horizons Forum and Aerospace Exposition, No. January, American Institute of Aeronautics and Astronautics, Nashville, Tennessee, 2012, pp. 1-15.

10 Niezgodka, F.-J., Der Hyperschallwindkanal H2K des DLR in Köln-Porz (Stand 2000), DLRMitteilungen, Deutsches Zentrum für Luft- und Raumfahrt e. V., Köln, 2001.

11 Henckels, A. and Gruhn, P., "Study on Aerothermal Effects of Viscous Shock Interaction in Hypersonic Inlets," Proceedings of the Fifth European Symposium on Aerothermodynamics for Space Vehicles, European Space Agency, Cologne, 2004, pp. 553-558. 